\title{
EI delito contable y la necesidad de implementar Programas de Cumplimiento Penal en la empresa para evitar su comisión
}

The accounting crime and the need to implement criminal Compliance Programs in the company to prevent it from being committed

\author{
Dra. María Concepción RAYÓN BALLESTEROS \\ Universidad Complutense de Madrid \\ mcrayon@ucm.es \\ Dr. José Manuel SANTOS JAÉN \\ Universidad de Murcia \\ jmsj1@um.es
}

Resumen: En este artículo se analiza el delito contable y la necesidad de implementar en las empresas sistemas de vigilancia y control para evitar la comisión de ese delito en su seno. Se hace referencia a los tres aspectos más relevantes a considerar: la implantación de un plan de cumplimiento penal o Compliance Program, la designación del Oficial de Cumplimiento o Compliance Officer y la instauración de un Canal de Denuncias o Whistleblowing Channel.

\footnotetext{
Abstract: This article analyzes accounting crime and the need to implement surveillance and control systems in companies to prevent the commission of this crime within them. It refers to the three most relevant aspects to be considered: the implementation of a Criminal Compliance Program, the appointment of the Compliance Officer and the establishment of a Whistleblowing Channel.
}

Palabras clave: Canal de Denuncias, delito contable, información asimétrica contable, información financiera, Oficial de Cumplimiento, Programa de Cumplimiento Penal.

Keywords: Whistleblowing Channel, accounting crime, assymetric accounting information financial information, Compliance Officer, Criminal Compliance Program 
Sumario:

I. Presentación.

II. EI delito contable.

2.1. La ubicación del delito y el sujeto activo.

2.2. La conducta típica.

2.3. Técnicas de manipulación de la información.

III. La necesidad de vigilancia y control que recae en la empresa para evitar la comisión del delito.

3.1. La implantación del Plan de Cumplimiento o Compliance Program.

3.2. La designación del Oficial de Cumplimiento o Compliance Officer.

3.3. La instauración y gestión de un Canal de Denuncias o Whistleblowing Channel.

IV. Conclusiones.

V. Bibliografía.

Recibido: septiembre 2020.

Aceptado: noviembre 2020. 


\section{PRESENTACIÓN}

Entre la diversidad de delitos que pueden conllevar responsabilidad penal para las personas jurídicas, se encuentran los delitos contables. Dentro de los delitos societarios, el Código Penal en su Capítulo XIII artículo 290 establece lo siguiente:

"Los administradores, de hecho o de derecho, de una sociedad constituida $o$ en formación, que falsearen las cuentas anuales u otros documentos que deban reflejar la situación jurídica o económica de la entidad, de forma idónea para causar un perjuicio económico a la misma, a alguno de sus socios, o a un tercero, serán castigados con la pena de prisión de uno a tres años y multa de seis a doce meses."

El estudio de esta tipología delictiva se hace más que necesaria en un momento como en el actual, en el que la pandemia generada por la COVID-19 ha llevado a la economía española a adentrarse en una crisis sin precedentes, en la que se espera una fuerte contracción de la producción y destrucción del empleo, con las graves consecuencias sociales que esto va a suponer. Para poder remontar la senda del crecimiento económico y la generación de empleo, se hace más que necesaria recuperar la confianza en el sistema económico. Confianza esta que se ha visto limada en los últimos años a consecuencia de una serie de importantes escándalos económicos en los que ha planeado la sombre del delito contable. De ahí la importancia del estudio del mismo, así como de las consecuencias para las personas jurídicas en las que tiene lugar su comisión y las premisas que se han de llevar a cabo para evitar la responsabilidad aparejada a este tipo de acciones delictivas.

Además, en esta línea, es necesario destacar que en las empresas resulta imprescindible que sus administradores y directivos adopten las medidas necesarias para que cumplir con las obligaciones exigidas por el Código Penal en cuanto a sus deberes de vigilancia y control detectando posibles desviaciones para sancionarlas.

Para comenzar, es importante señalar que este delito contable es diferente al conocido como delito contable fiscal, regulado por el Código Penal en su 
artículo 310, que es aquel que causa un perjuicio directo a la Hacienda Pública o la Seguridad Social. Se trata de dos delitos que guardan un gran número de semejanzas, principalmente en cuanto a su comisión mediante la alteración de los documentos contables. Sin embargo, la principal diferencia entre ambos radica en la naturaleza del sujeto pasivo, ya que como veremos en el desarrollo de este delito contable, el sujeto pasivo del delito recogido en el artículo 290 del código penal puede ser la propia sociedad, los socios o un tercero, mientras que en el supuesto del delito regulado en el artículo 310, el sujeto pasivo es el acreedor tributario.

En definitiva, si bien ambos delitos suponen la realización de información contable no veraz, el de carácter fiscal va dirigido a cometer una defraudación de las obligaciones con el erario público. También conviene señalar que hay supuestos en los que no se cumple con lo regulado en el artículo 310 y residualmente puede ser de aplicación el delito contable.

En el caso de que el delito contable sea cometido en el seno de una empresa esta incurre en responsabilidad penal conforme a la reforma del Código Penal operada por la Ley Orgánica 1/2015 que introduce una mejora técnica generalizada en la regulación de la responsabilidad penal de las personas jurídicas, con varias finalidades concretas:

- Delimitar su contenido.

- Ampliar su ámbito de responsabilidad para incluir los actos de cualquier persona con capacidad decisoria o facultades organizativas o de control.

- Reconocer de forma expresa, como causa de exención de responsabilidad penal de la persona jurídica, del establecimiento de un Programa de Cumplimiento Penal en el artículo 31 bis núm. 2 CP.

- Igualmente la nueva regulación determina, en el artículo 31 bis núm. 5, los requisitos de los Programas de Cumplimiento Penal para ser adecuados y funcionar de forma eficaz e introduce el artículo 31 ter, que establece la exigibilidad de la responsabilidad penal de las personas jurídicas siempre que se constate la comisión del delito que haya tenido que cometerse por quien ostente los cargos o funciones de representación e igualmente establece el mantenimiento de las circunstancias concretas de atenuación de la pena en el artículo 31 quater.

Por otro lado, hay que considerar que el Código Penal enfatiza actualmente la obligación de vigilancia y control que recae en las empresas para que no se 
cometan delitos en su seno. Precisamente el incumplimiento de esta obligación puede dar lugar a la responsabilidad penal de la empresa, por lo que resulta particularmente interesante conocer el modo adecuado de proceder y prevenir eficazmente la comisión de delitos.

En el presente artículo vamos a hacer especial referencia al delito contable y sus implicaciones, analizando posteriormente la necesaria obligación de vigilancia en la empresa para evitar la comisión de este tipo de delito. Destacaremos únicamente tres pilares básicos: la implementación del Programa de Cumplimiento o Compliance Program, la designación del Oficial de Cumplimiento o Compliance Officer y la instauración del Canal de Denuncias o Whistleblowing Channel. Dejaremos al margen de este breve artículo la referencia específica otros aspectos fundamentales relacionados con el deber de vigilancia y control por parte de la empresa como la instauración del Código Ético o de buenas prácticas, el protocolo de actuación para investigaciones internas y el régimen sancionador, aunque haremos una breve referencia a los mismos integrándolos dentro del Programa de Cumplimiento, al ser algunos de sus elementos.

\section{EL DELITO CONTABLE}

El delito contable es un delito especial y propio, el cual requiere que el sujeto activo sea administrador, de hecho o de derecho de una sociedad y lleve a cabo una conducta dolosa ${ }^{1}$. También es posible, según establece la Jurisprudencia ${ }^{2}$ la participación del extraneus como inductor y/o colaborador, sancionándose las falsedades recaídas sobre cualquier documento que recoja la información financiera y jurídica de la compañía.

Se trata de un delito del cual ya tenemos noticias de su comisión en el siglo $\mathrm{XIX}^{3}$, si bien no se encuentra regulación expresa hasta el Código Penal de 1928. Y es ya con el Código Penal de 1995 donde se ubica dentro de los llamados delitos societarios.

El orden socio económico es el objeto de tutela mediante la tipificación de este delito, ya que el bien jurídico protegido no es otro, sino la calidad de la información económico-financiera que permita un normal desarrollo de la economía imprescindible para el normal funcionamiento del sistema económico

\footnotetext{
${ }^{1}$ Véase MONFORTE MAYORAL, J., "Entre la contabilidad creativa y el delito contable", en Diario La Ley, el 17 de abril, (2020) 1-7.

${ }^{2}$ STS de 5 de septiembre de 2005.

${ }^{3}$ Así en la primera mitad del siglo XIV se produjo un intento de regulación en el ámbito penal de las irregularidades cometidas en la información contable.
} 
de cualquier Estado. Por lo tanto, la manipulación de la información financiera pone en riesgo la confianza en el sistema económico y puede llegar a crear riesgos de desestabilización de magnitudes incalculables.

\subsection{La ubicación del delito y el sujeto activo}

A la hora de clasificar la conducta asociada a este delito, es posible ubicarlo en distintas clasificaciones de la siguiente forma ${ }^{4}$ :

- Respecto al bien jurídico protegido:

- Delito que protege el patrimonio individual, ya sea de la sociedad, de los socios o de un tercero.

- Delito que protege otros bienes jurídicos distintos al patrimonio.

- Respecto a las consecuencias para el bien jurídico de carácter colectivo:

- Delito de peligro.

- Delito de lesión.

- Respecto a quienes son los titulares de los intereses protegidos:

- Delito contra la sociedad.

- Delito contra los socios.

- Delito contra terceros.

- Respecto a la figura del sujeto activo:

- Delito especial propio, los administradores de hecho y de derecho.

- Respecto a la autoría:

- Delito en donde el autor infringe un deber extrapenal, legal o contractual, que le es exigido para garantizar el bien jurídico protegido.

- Delitos en donde el autor no tiene por qué encontrarse en una posición previa de deber con respecto al bien jurídico protegido.

\footnotetext{
${ }^{4}$ DÍAZ-MAROTO J., y POLO-VEREDA, J., "Clasificación de las conductas prosociales", disponible en https://starviewerteam.com/2011/06/20/conducta-prosocial-empatia-responsabilidady-la-ecuacion-de-decision/
} 
En referencia a la figura del sujeto activo, aun partiendo de posiciones divergentes y ante la ausencia de definición concreta por parte del legislador, han sido los tribunales civiles y penales quienes han llegado a definir qué se entiende por administrador de hecho de una sociedad mercantil ${ }^{5}$. De tal manera, que actualmente podemos considerar como administradores de hecho a aquellas personas que de facto y sin necesidad de que medie nombramiento legal, desarrollen funciones de administración, entre las que se destacan la realización de la documentación económico-financiera y el sometimiento a su aprobación por la Junta General. Aprobación esta que no exime de responsabilidad a los administradores. Esta imposibilidad de eximir la responsabilidad por la aprobación del órgano supremo de la sociedad pretende evitar la inoperatividad que resultaría de permitir salvar esta responsabilidad, ya que en este caso los administradores diligentes someterían a aprobación de la Junta General cualquier tipo de decisión trascendental, lo que sería totalmente inoperativo debido a la dificultad para reunir a la Junta General con cierta regularidad ${ }^{6}$.

En relación a la actuación de los administradores de hecho, para dilucidar su responsabilidad se requiere de una verdadera investigación acerca de los roles desempeñados dentro de la sociedad, ya que en el caso de un administrador de hecho, su condición ha de ser atribuida por el hecho llevar a cabo el verdadero ejercicio de la administración de la sociedad, de tal forma, que el apoderado por parte de la sociedad a una persona no administradora ha sido considerado por los tribunales como administrador de hecho. No así el mero encargado de realizar los documentos contables, el cual carece de autonomía y por tanto se limita a procesar la documentación recibida.

Debido a las muchas casuísticas y entramados organizativos y empresariales con los que operan algunos grupos de sociedades, en ocasiones resulta imposible determinar el nivel de participación de cada individuo en la comisión de un delito contable, pudiéndose llegar a declarar la responsabilidad penal de la persona jurídica aun en el supuesto en el que haya sido imposible llevar a cabo la individualización de la responsabilidad de las personas físicas.

En cuanto a la tentativa, la misma no se admite, ya que hasta el último momento de la presentación de las cuentas anuales el administrador puede corregir lo hecho y presentar unas cuentas que reflejen la imagen fiel del patrimonio, de la situación financiera y de los resultados de la empresa.

\footnotetext{
${ }^{5}$ ASTARLOA, E., “¿Por fin un concepto unívoco de administrado de hecho en Derecho penal y Derecho societario?”. En Actualidad Jurídica, 1 (2011) 60-67.

${ }^{6}$ OLMEDO PERALTA, E., La responsabilidad contable en el gobierno corporativo de las sociedades de capital, Madrid 2014, p. 83.
} 


\subsection{La conducta típica}

A la hora de concretar la conductiva típica, el Plan General de Contabilidad ${ }^{7}$ en su primera parte denominada Marco Conceptual de la Contabilidad, punto $2^{\circ}$ establece que:

La información incluida en las cuentas anuales debe ser relevante y fiable.

La información es relevante cuando es útil para la toma de decisiones económicas, es decir, cuando ayuda a evaluar sucesos pasados, presentes o futuros, o bien a confirmar o corregir evaluaciones realizadas anteriormente. En particular, para cumplir con este requisito, las cuentas anuales deben mostrar adecuadamente los riesgos a los que se enfrenta la empresa. La información es fiable cuando está libre de errores materiales y es neutral, es decir, está libre de sesgos, y los usuarios pueden confiar en que es la imagen fiel de lo que pretende representar.

Una cualidad derivada de la fiabilidad es la integridad, que se alcanza cuando la información financiera contiene, de forma completa, todos los datos que pueden influir en la toma de decisiones, sin ninguna omisión de información significativa.

De tal manera, que nos encontramos ante un delito de falsedad documental "consistente, en la mayoría de los supuestos, en faltar a la verdad en la narración de los hechos por parte de las personas encargadas de confeccionar los documentos que han de servir para dejar constancia del estado real económico o jurídico de la entidad mercantil”"8.

La falsedad documental por su parte, se encuentra recogida en el artículo 392 del Código Penal, en el que se establecen penas para aquellos particulares que cometieran falsedad en documento mercantil. En referencia al delito que nos atañe, se considera falsedad cualquier alteración de la verdadera realidad económico-financiera de una sociedad, como se apuntó antes, no solo de sus cuentas anuales, comprendidas por el balance, la cuenta de pérdidas y ganancia, el estado de flujos de efecto, el estado de cambios en el patrimonio neto y la memoria. Sino que otra serie de documentos relacionados con la situación económico-financiera de la sociedad, entre los que cabe destacar: el informe de gestión, el informe de información no financiera, la propuesta de distribución de resultados y el libro de actas. En este mismo sentido, la sala Segunda, de

\footnotetext{
${ }^{7}$ Real Decreto 1514/2007, de 16 de noviembre, por el que se aprueba el Plan General de Contabilidad. B.O.E. 20 de noviembre con vigencia 1 de enero de 2008.

${ }^{8}$ PAVÓN-HERRADÓN, D., El delito de falsedad en los documetnos sociales del artículo 290 del código penal, [Universidad Complutense de Madrid], disponible en http://www.javeriana.edu.co/ biblos/tesis/derecho/dere1/Tesis35.pdf.
} 
lo Penal del Tribunal Supremo ${ }^{9}$ en relación al delito contable, afirma lo siguiente:

La conducta típica consiste en falsear las cuentas anuales $u$ otros documentos que deban reflejar la situación jurídica o económica de la entidad, de forma idónea para causar un perjuicio económico a la misma, a alguno de sus socios o a un tercero.

La falsedad, tal y como afirma el Tribunal Supremo ${ }^{10}$ puede ser material cuando afecta a la estructura física de un documento, por ejemplo, el balance de la sociedad o ideológica cuando afecta a la veracidad de lo declarado.

En el delito contable se hace imprescindible la necesidad de dolo para su perfección, sin que sea posible la comisión culposa ${ }^{11}$. En este sentido, puede suponer la exoneración del verdadero autor de la falsedad documental por falta de autores. Es conveniente reseñar que el Tribunal Supremo ${ }^{12}$ dictamina que la exoneración de responsabilidad de un director financiero autor material de la falsificación de la documentación contable de una sociedad, y por lo tanto, cooperador necesario ante el delito recogido en el artículo 290 del Código Penal debido a la ausencia de autores materiales, ya que los miembros del Consejo de Administración no actuaron de manera dolosa al no ser conscientes de la falsedad documental, debido a la "confianza" depositada en su director financiero.

\subsection{Técnicas de manipulación de la información}

Volviendo a la conducta típica consistente en cualquier acción tendente a impedir el reflejo de la imagen fiel por parte de la contabilidad, esta se encuentra directamente relacionada con la llamada manipulación contable. La manipulación de la información contable puede llevarse a cabo mediante distintas técnicas, siendo las más habituales la gestión del beneficio, el alisamiento de resultados y la contabilidad creativa ${ }^{13}$. Son muchas las definiciones arrojadas por los expertos en la materia contable sobre el termino manipulación contable. En cualquier caso, se trata de cualquier técnica o comportamiento empleado por la dirección

${ }^{9}$ STS de 9 de mayo de 2005.

${ }^{10}$ STS de 2 de abril de 2013.

${ }^{11}$ GELABER-MORRO, F.M., y SANTOS-JAÉN, J. M., "El delito contable. Estudio de la comisión de delitos contables a través de casos mediáticos", en La razón histórica (Murcia), 45 (2020) 18-41.

${ }^{12}$ STS de 18 de marzo de 2014.

13 AMAT, O., y ELVIRA, O., "Manipulación contable: tipología y prácticas utilizadas", en Revista Internacional Legis de Contabilidad y Auditoria, disponible en http://www.oriolamat.cat/ wordpress/wp-content/uploads/2017/04/Manipulaci\%C3\%B3n-contable-tipolog $\% \mathrm{C} 3 \% \mathrm{ADa}-\mathrm{y}-\mathrm{pr} \% \mathrm{C} 3 \%$ Alcticas-utilizadas-Revista-Internacional-Legis-de-Contabilidad-Auditor\%C3\%ADa-2007.pdf. 
de la sociedad para mediante el incumplimiento de los principios contables generalmente aceptados reflejar una situación de la imagen fiel del patrimonio, de la situación financiera y de los resultados de la empresa distinta a la real.

Como se apuntaba antes, entre las distintas técnicas que llevan a la manipulación contable podemos encontrarnos con la contabilidad creativa, consistente en mediante el uso de las diferentes opciones que permite la normativa contable, construir una información financiera ad hoc distinta a la que mostraría la realidad de la compañía. Esto requerirá o bien el incumplimiento de los principios contables o en su caso abandonar la uniformidad del mismo. El objetivo será mostrar una imagen adecuada a las necesidades de la Sociedad. Así si por ejemplo se piensa acudir al mercado financiero para solicitar una operación crediticia, la sociedad puede modificar la información sobre el vencimiento de ciertas deudas para obtener unos mejores indicadores de liquidez. Otro supuesto podría modificar el criterio para la gestión de existencias ${ }^{14} \mathrm{o}$ el porcentaje de amortización de los activos sin una justificación que lo soporte y conseguir así la obtención de la cifra de resultados deseada.

La flexibilidad que permiten ciertos principios contables otorgan a las sociedades cierta discrecionalidad a la hora de estimar los resultados del ejercicio, las cuales podrían no reflejar con precisión las condiciones subyacentes de la sociedad, esto genera un comportamiento oportunista conocido como gestión del beneficio o "earnings management"15. El objetivo principal suele ser aumentar el valor de la sociedad para atraer a inversores o para aumentar la remuneración de los directivos en los casos en los que está ligada a los resultados de la sociedad ${ }^{16}$.

Las fluctuaciones en los beneficios empresariales pueden provocar una pérdida de confianza por parte de inversores y prestamistas, de ahí que determinadas compañías lleven a cabo actuaciones tendentes a conseguir eliminar estas fluctuaciones y aumentar la confianza de los "stakeholders". Una técnica utilizada para conseguir acabar con los problemas de fluctuaciones puede ser la realización de transacciones artificiales entre empresas, lo que permite controlar ciertos ingresos y gastos en varios ejercicios ${ }^{17}$.

${ }^{14}$ FIFO o Coste Medio Ponderado.

15 PALACIOS-MANZANO, M.; GRAS-GIL, E., y SANTOS-JAÉN, J.M., "Corporate Social Responsibility and its effect on earnings managements: an empirical research on Spanish firms", en Total Quality Management and Business Excellence (Londrés), 3 (2020) 82-111.

${ }^{16}$ Esto se puede conseguir con la modificación de las amortizaciones o provisiones, ya que, a pesar de cambiar el resultado contable, no suponen un flujo monetario.

${ }^{17}$ AMAT, O., y ELVIRA, O., op. cit. 
Además de las operaciones que han sido descritas en los párrafos anteriores, como uso de las provisiones y amortizaciones, la realización de transacciones artificiales o los cambios en los métodos de gestión de existencias, las empresas también pueden aprovechar el margen que permiten las normas contables a la hora de contabilizar determinados gastos e ingresos, como la activación de gastos de investigación y desarrollo, de gastos financieros por adquisición de inmovilizados, etc.

Resulta importante diferenciar entre una política contable conservadora o agresiva implementada por una empresa respetando los principios contables, y de manera muy especial su uniformidad, con la manipulación contable dirigida a alterar el resultado natural de la empresa (Monterrey Mayoral, 2002).

Este tipo de técnicas con las que se consigue alterar la información contenida en las cuentas anuales u otros estados financieros, en un importante número de casos se amparan en vacíos y/o grandes dosis de discrecionalidad que permite la normativa contable, y por lo tanto, a pesar de impedir el reflejo de la imagen fiel, no suponen la comisión de una acción punible en términos de falsedad, tal y como se ha visto en el artículo 290 del Código Penal. Siendo por otra parte, muy difusa la frontera que separa una contabilidad creativa de una contabilidad falseada y por lo tanto objeto punible en base al artículo 290 del Código Penal. De ahí que sea más que necesario que las normas contables reduzcan a la mínima expresión la posibilidad de aplicar técnicas de manipulación de manera legal ${ }^{18}$.

Para reducir la posibilidad de información contable asimétrica, además de la eliminación de la discrecionalidad en la aplicación de ciertas normas, como ya se ha apuntado, se debe de ahondar en otras dos medidas muy distintas:

- Mejorar el papel de los auditores de cuentas, como expertos independientes encargados de verificar el cumplimiento de la obligación de mostrar la imagen fiel por parte de la contabilidad. Para ello se hace necesario asegurar la debida independencia entre los auditores y las firmas auditadas, ya que esta falta de independencia del auditor frente a la compañía puede provocar una pérdida de la neutralidad necesaria para llevar a cabo su trabajo por parte

${ }^{18}$ Según un estudio realizado por AMAT, O., Empresas que mienten. Cómo maquillan las cuentas y cómo detectarlo a tiempo, Barcelona 2007, p.67., entre un 30-50\% de empresas modifican sus cuentas de manera legal, debido a la flexibilidad a la hora de aplicar determinados principios contables y entre un $10-15 \%$ de empresas se exceden de lo permitido y cometen delito contable, tal y como ha sido considerado a lo largo de este trabajo. De tal manera que entre un $40-65 \%$ de empresas manipulan en cierta medida sus resultados. 
del auditor ${ }^{19}$. La independencia del auditor es el pilar básico y fundamental en la que reside la confianza en el auditor y su informe ${ }^{20}$. El legislador comunitario y español, consciente de la necesidad de poner fin a cualquier situación que ponga en riesgo la independencia del auditor, ha llevado a cabo en los últimos años varias reformas de la legislación en materia de auditoria para salvaguardar, mediante su fortalecimiento, la independencia de los auditores, tal y como puede observarse en la siguiente imagen:

\section{EVOLUCIÓN DE LA NORMATIVA COMUNITARIA EUROPEA EN MATERIA DE INDEPENDENCIA}

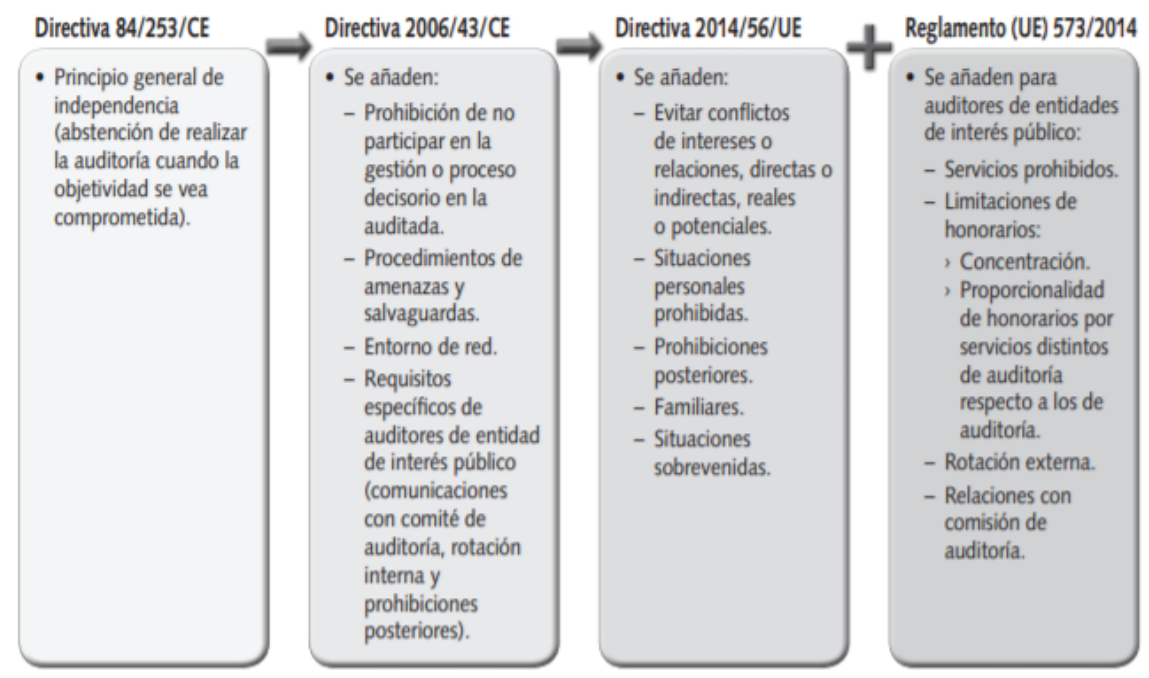

Fuente: RUBIO-HERRERA, E., op. cit.

Sin embargo, casos mediáticos como el de Abengoa o Bankia, con entidades en las que se ha demostrado una manipulación contable no reflejada en el informe de auditoría, ponen claramente de manifiesto la insuficiencia de las medidas adoptadas y requiere de una regulación especialmente restrictiva en cuanto a los servicios que las entidades de auditoria prestan a las empresas que auditan distintos del servicio de auditoria de sus cuentas anuales.

- Incrementar la presencia de los comités de auditoría en las empresas. Estos órganos creados con el objetivo de asegurar la independencia de los audi-

${ }^{19}$ ROMERO-GARCÍA, J.E.; LÓPEZ-GAVIRA, M. R., y PÉREZ-LOPEZ, J. A., "Servicios adicionales de auditoría. Independencia del auditor y permisividad de la legislación", en Revista de Ciencias Sociales, 4 (2017) 9-22.

${ }^{20}$ RUBIO-HERRERA, E., "El deber de independencia de los auditores según la nueva normativa", en Revista Española de Control Externo, 52 (2016) 59-101. 
tores así como la integridad de la información contable ${ }^{21}$, son de obligada incorporación en las empresas cotizadas desde el año 2002 y desde finales de 2014 el ordenamiento jurídico español establece la obligación de que sus miembros sean exclusivamente por miembros no directivos de la compañía y al menos 2 de cada 3 han de ser independientes. Muchos estudios empíricos han demostrado cómo cuanto mayor y más independiente es este órgano menor es la manipulación del resultado por parte de las compañías ${ }^{22}$ (Allegrini $\&$ Greco, 2011). De tal manera que, en aras de conseguir reducir la asimetría en la información contable, se debería de establecer la obligatoriedad para aquellas empresas que superen un cierto tamaño, podría establecerse el mismo límite que existe para formular cuenta de pérdidas y ganancias normal, de contar con un comité de auditoría.

\section{LA NECESIDAD DE VIGILANCIA Y CONTROL QUE RECAE EN LA EMPRESA PARA EVITAR LA COMISIÓN DEL DELITO}

Tal y como hemos indicado anteriormente, el Código Penal español hace énfasis en la obligación de vigilancia que recae en las empresas para que no se cometan delitos en su seno. Precisamente el incumplimiento de esta obligación puede dar lugar a su responsabilidad penal, salvo que el empresario demuestre que fue cauteloso y empleó todos los mecanismos necesarios para prevenir conductas delictivas dentro de su organización.

Por eso para evitar que el delito contable sea cometido en el seno de la empresa esta debe instaurar una serie de mecanismos que lo impidan. El incumplimiento de esta obligación genera su consiguiente responsabilidad penal.

En este artículo nos referiremos a la necesidad de implementar un programa de cumplimiento penal o Compliance Program. Además, al Compliance Officer y los órganos de cumplimento que adquieren una gran relevancia en relación con la investigación y prueba del delito. Y también consideraremos especialmente la activación de un Canal de Denuncias o Whistleblowing Channel. Estos tres temas constituyen los tres pilares fundamentales para luchar contra la comisión de los delitos en el seno de la empresa y a ellos nos referiremos seguidamente. Y vamos a referirnos a estos términos en castellano y en inglés indistintamente dado que se vienen conociendo así en el argot que se utiliza en el ámbito jurídico y empresarial.

${ }^{21}$ GARCÍA-BENAU, M.A.; PUCHETA-MARTÍNEZ, M.C., y ZORIO-GRIMA, A. "Los Comités de Auditoría ¿útiles y necesarios?”, en Revista de Contabilidad, 6 (2003) 87-121.

${ }^{22}$ ALLEGRINI, M., y GRECO, G., "Corporate boards, audit committes and voluntary disclosure: evidence from Italian Listed Companies”, en Journal of Management and Governance, 15 (2011) 1-30. 
Tal y como hemos indicado anteriormente, dejaremos al margen de referencia específica otros aspectos fundamentales relacionados con el deber de vigilancia y control por parte de la empresa como la instauración del Código Ético o de buenas prácticas, el protocolo de actuación para investigaciones internas y el régimen sancionador, aunque haremos una breve referencia a los mismos integrándolos dentro del Programa de Cumplimiento, al ser algunos de sus elementos.

\subsection{La implantación del Plan de Cumplimiento o Compliance Program}

El programa de cumplimento ${ }^{23}$ es el protocolo integrado orgánica, jerárquica y estatutariamente en la persona jurídica para evitar conductas del personal que puedan poner en riesgo a la empresa por la comisión de hechos delictivos en su seno, lo que conllevaría su responsabilidad penal ${ }^{24}$.

Como es obvio, la elaboración de los elementos que integran el programa de cumplimiento debe ser muy minuciosa y detallada, adaptada a cada empresa particular $^{25}$. Para su correcta elaboración se deben tener en cuenta aspectos muy variados y específicos de cada empresa como el sector de dedicación, el número de trabajadores y el tamaño de la empresa, el volumen de facturación, los valores de la misma, entre otros.

${ }^{23}$ Los programas de cumplimiento se vienen imponiendo desde hace más de cien años en Estados Unidos, sin embargo, desde los años 70 del siglo XX se implantaron las Securities and Exchange Comission en EEUU, junto con Foreign Corrupt Parctices Act para proteger a los inversores, prevenir la corrupción y gestionar con transparencia los mercados de valores. En 1991 las Guidelines for Sentencing Organizations establecieron los criterios para implantar los programas de cumplimento junto con los requisitos que debían contener los mismos para ser eficaces. http://www.ussc.gov/guidelines-manual/organizational-guidelines, que es la web de la United States Sentencing Comissión. Tiene el siguiente contenido: Overview of the Organizational Guidelines, Organizational Guidelines Fine Primer, USSC Guidelines Manual, Special Reports and Discussions on Chapter Eight, Selected Articles and Materials on Chapter Eight, Supplementary Report on Sentencing Guidelines for Organizations (August 1991), Discussion Materials on Organizational Sanctions (July 1988).

En Europa estos planes fueron impulsados por la Unión Europea al haberse consagrado previamente en la OCDE y Naciones Unidas. Concretamente la Convención de Naciones Unidas contra la corrupción establece en su artículo 26 que "Cada Estado Parte adoptará las medidas que sean necesarias, en consonancia con sus principios jurídicos, a fin de establecer la responsabilidad de las personas jurídicas por su participación en delitos tipificados con arreglo a la presente Convención".

${ }^{24}$ Sobre las primeras definiciones de los programas de cumplimiento o Compliance Penal destacamos BACIGALUPO, E. Compliance y Derecho Penal, Editorial Aranzadi, Zizur Menor, 2011, p. 17 y ss. Para vigencia actual Vid. Practicum Compliance 2020, Ed. Aranzadi, Zizur Menor, 2020.

${ }^{25}$ GÓMEZ-JARA DÍEZ, C. La responsabilidad penal de las empresas en los Estados Unidos, Centro de Estudios Ramón Areces, Madrid, 2006. También Practicum Compliance 2020, o.c. 
Las empresas, y las personas jurídicas en general, deben establecer este tipo de programas para documentar que han actuado diligentemente en la prevención y vigilancia de delitos en su seno.

Obviamente la justificación primordial de la existencia de los programas de cumplimiento penal es evitar riesgos penales para conseguir la atenuación o exención de responsabilidad penal en el caso de que se cometa un delito por la persona jurídica, pero también se consiguen ventajas relevantes como generar una cultura ética empresarial del cumplimiento, evitar daños reputacionales o la pérdida de confianza de los accionistas, proveedores, trabajadores o clientes, entre otros. En general podemos destacar que los planes de cumplimiento suponen la fuerza coactiva del derecho para imponer la cultura empresarial de la ética y el cumplimiento legal ${ }^{26}$.

El proceso a seguir para su elaboración y funcionamiento sería, básicamente expuesto, el siguiente:

- Fijar inicialmente los objetivos concretos que se persiguen.

- Estudiar la normativa aplicable con la evaluación de los correspondientes riesgos, tanto internos como externos.

- Realizar el diagnóstico de situación considerando los principios de buen gobierno.

- Planificar los objetivos por los órganos de gobierno y el equipo directivo que, además, se compromete a desarrollar a implementar el plan correspondiente.

- Desarrollar el plan operacional y de control a seguir con la elaboración del programa concretos

- Implantar el plan, lo que requiere formación de los empleados y establecimiento de canales de comunicación para la evaluación y monitorización de los resultados. Igualmente se planificarán las auditorías y revisiones necesarias.

- Analizar los posibles fallos de cumplimiento de manera que puedan implementarse las mejoras necesarias en el futuro.

${ }^{26}$ En este sentido podemos destacar la sentencia del Tribunal Supremo 318/2018, de 28 de junio que afirma "una buena praxis corporativa en la empresa es la de implementar estos programas de cumplimiento normativo que garantice que este tipo de hechos no se comentan, o dificulten las acciones continuadas de distracción de dinero, o abuso de funciones que un buen programa de cumplimiento normativo hubiera detectado de inmediato". 
En cuanto a los requisitos de los programas de cumplimiento para que sean efectivos resulta determinante el artículo 31 bis.5 del Código Penal ${ }^{27}$ que establece: Los modelos de organización y gestión deberán cumplir los siguientes requisitos:

- $1 .^{\circ}$ Identificarán las actividades en cuyo ámbito puedan ser cometidos los delitos que deben ser prevenidos.

- 2. ${ }^{\circ}$ Establecerán los protocolos o procedimientos que concreten el proceso de formación de la voluntad de la persona jurídica, de adopción de decisiones y de ejecución de las mismas con relación a aquéllos.

- 3. ${ }^{\circ}$ Dispondrán de modelos de gestión de los recursos financieros adecuados para impedir la comisión de los delitos que deben ser prevenidos.

- 4. ${ }^{\circ}$ Impondrán la obligación de informar de posibles riesgos e incumplimientos al organismo encargado de vigilar el funcionamiento y observancia del modelo de prevención.

- 5. ${ }^{\circ}$ Establecerán un sistema disciplinario que sancione adecuadamente el incumplimiento de las medidas que establezca el modelo.

- $6 .^{\circ}$ Realizarán una verificación periódica del modelo y de su eventual modificación cuando se pongan de manifiesto infracciones relevantes de sus disposiciones, o cuando se produzcan cambios en la organización, en la estructura de control o en la actividad desarrollada que los hagan necesarios.

Aunque el Código Penal ya precisa el contenido de estos planes para que sean eficaces, además resultan relevantes otras normas como las siguientes:

- Gestión del Riesgo. Técnicas de apreciación del riesgo (UNE-EN 31010: 2011).

- Sistema de Gestión de Compliance Penal (UNE 19601:2017) que constituye el pilar sobre el que se asientan los sistemas de Compliance que tratan de adecuarse al Código Penal Español. Establece los requisitos para poner en marcha un sistema de gestión de Compliance.

${ }^{27}$ Artículo 31 bis redactado por el número veinte del artículo único de la L.O. 1/2015, de 30 de marzo, por la que se modifica la L.O. 10/1995, de 23 de noviembre, del Código Penal. B.O.E. de 31 marzo de 2015 y vigencia de 1de julio de 2015 . 
EL DELITO CONTABLE Y LA NECESIDAD DE IMPLEMENTAR PROGRAMAS... 111

- Identificar, analizar y evaluar los riesgos penales.

- Disponer de recursos financieros, adecuados y suficientes para conseguir los objetivos del modelo.

- Usar procedimientos para la puesta en conocimiento de las conductas potencialmente delictivas.

- Adoptar acciones disciplinarias si se producen incumplimientos de los elementos del sistema de gestión.

- Supervisar el sistema por parte del órgano de Compliance penal.

- Crear una cultura en la que se integren la política y el sistema de gestión de Compliance.

- Sistema de Gestión Antisoborno (UNE-ISO 37001:2017) que aporta las recomendaciones necesarias para ayudar a la empresa a combatir el soborno y promover una cultura empresarial ética.

- Gestión de la Seguridad de la Información (ISO 27001:2017) que busca concretar la gestión en el ámbito de la seguridad de la información.

- Sistema de Gestión de Compliance Tributario (UNE 19602:2019) que indica los requisitos específicos para el cumplimiento de la normativa tributaria española y comunitaria y la gestión de riesgos.

El programa de cumplimento consta de varios elementos relacionados entre sí como son el Código Ético o de buenas prácticas, el Canal de Denuncias, el protocolo de actuación para investigaciones internas, los controles generales y específicos, el catálogo de medidas tendentes a evitar el incumplimiento de las normas por parte de los miembros de una empresa, así como el régimen sancionador para el incumplimiento de las medidas contenidas en el programa ${ }^{28}$.

Los programas de cumplimiento se convierten en la forma de instaurar la cultura del cumplimiento en la empresa y serán prueba relevante en el proceso penal como cualquier prueba documental siempre que cumpla los requisitos establecidos en las normas que regulan las garantías procesales y los derechos fundamentales y se aporten al procedimiento en el momento procesal oportuno.

${ }^{28}$ GIMENO BEVIÁ, J., Compliance y proceso penal. El proceso penal de las personas jurídicas. Editorial Aranzadi S.A, Zizur Menor, 2016, pp. 248-249. 
El programa se aportará al proceso como prueba documental integrado por sus mapas de riesgos y sus análisis y evaluaciones, con su desarrollo de su Código Ético, con los archivos de las formaciones y los datos de las informaciones facilitadas a los trabajadores, con los archivos de todos los controles efectuados y las fechas, con el diseño y la forma de funcionamiento del Canal de Denuncias, con los registros de actividad realizado por el órgano de cumplimiento, con el resultado de las investigaciones internas llevadas a cabo, entre otras informaciones relevantes, y todo ello perfectamente datado y calendarizado para conocer las fechas efectivas de los controles y análisis efectuados ${ }^{29}$.

\subsection{La designación del Oficial de Cumplimiento o Compliance Officer}

El ordenamiento jurídico español no define esta figura tan relevante y necesaria, hoy en día, en la vida de la empresa ${ }^{30}$. Tampoco se definen claramente sus funciones o atribuciones, ni sus poderes para hacer cumplir sus pautas de actuación. En la Circular de la Fiscalía General del Estado 1/2016 si aparecen como notas características de actuación su autonomía, su independencia y su imparcialidad que son elevadas a condiciones sine qua non para las finalidades que debe perseguir ${ }^{31}$.

De las indicaciones que se contienen en dicha Circular de la Fiscalía General del Estado deducimos que claramente que debe tratarse de un órgano de la persona jurídica, creado específicamente por la misma y designado por su órgano de administración para asumir las funciones inherentes a su cargo ${ }^{32}$ y la vinculación concreta con la empresa podrá ser interna o externa por externalizarse el servicio.

${ }^{29}$ NEIRA PENA, A.M., Proceso penal y responsabilidad penal de las personas jurídicas. Editorial Aranzadi, S.A.U, Zizur Menor, 2017, p. 283: "Una vez que se ha concluido que tales programas de prevención delictiva son relevantes como objeto de prueba, se hace preciso determinar los medios probatorios idóneos para acreditar, no solo su existencia, sino también su efectiva implementación en el seno de la organización, así como su eficacia preventiva en relación con el delito enjuiciado".

${ }^{30} \mathrm{Ni}$ siquiera el Código Penal o las leyes procesales se refieren a esta figura, lo que demuestra que es una figura imprecisa. En la actualidad los abogados internos, auditores internos y personal de RRHH son los que vienen ejerciendo estas funciones, aunque la preparación que requiere este cargo genera como consecuencia que muchas empresas externalicen estos servicios.

${ }^{31}$ Sobre las investigaciones que realiza el Compliance Officer en el seno de la empresa resulta relevante: CUENCA MÁRQUEZ, J., y CABECERANS, J., "El Compliance Officer y los límites constitucionales de sus investigaciones", en Revista Aranzadi Doctrinal, 2 (2015) 65-73.

${ }^{32}$ Corresponderá al órgano de administración establecer la política de control y gestión de riesgos de la sociedad y su supervisión según la legislación vigente. 
Entre las responsabilidades del Compliance Officer se encuentran las siguientes $^{33}$ : elaborar los manuales internos, procedimientos y controles, asesorar en materia de cumplimiento normativo, supervisar y gestionar los esfuerzos de los diferentes departamentos para el cumplimiento de la legislación vigente, analizar cambios estatutarios y reguladores, velar y vigilar el cumplimiento del sistema de prevención de riesgos, controlar internamente a todos los miembros de la empresa para que no se cometan infracciones de dicho sistema de prevención de riesgos, denunciar y proponer sanciones para aquellas personas que hayan infringido ese código de conducta penal, evitar la existencia de riesgos penales en la empresa, monitorizar y actualizar periódicamente el plan de cumplimiento y reportar sobre posibles incumplimientos, asegurar la formación apropiada en materia reguladora de todo el personal, programar las auditorías para la comprobación del funcionamiento del sistema de control, actuar como enlace entre los organismos reguladores y las unidades de negocio de la entidad, y, lo más importante, documentar todo aquello que pueda constituir una prueba de que se ha actuado diligentemente en la prevención y vigilancia de delitos.

El Compliance Officer deberá ejercer sus funciones con poderes autónomos de iniciativa y control evitando posibles conflictos de intereses con la actuación de los órganos de administración y de dirección de la empresa. Además, desempeña sus funciones de supervisión, vigilancia y control ${ }^{34}$ y el incumplimiento de las mismas podría generar su responsabilidad penal ${ }^{35} \mathrm{o}$ incluso contractual o laboral.

${ }^{33}$ GARCÍA GARCÍA, V., Compliance: funciones especificar que se le deben asignar el Compliance Officer penal, disponible en https://elderecho.com/funciones-especificas-que-sele-deben-asignar-al-compliance-officer-penal. También puede verse por resultar muy interesante: ENSENYAT DE CARLOS, S. Manual del Compliance Officer. Guía práctica para los responsables de Compliance de habla hispana, Editorial Aranzadi, S.A., Zizur Menor, 2016, pp. 135-138.

${ }^{34}$ Ley Orgánica 10/1995, de 23 de noviembre, del Código Penal. ar31bis 2. 2a "la supervisión del funcionamiento y del cumplimiento del modelo de prevención implantado", y $4^{\text {a }}$ "no se ha producido una omisión o un ejercicio insuficiente de sus funciones de supervisión, vigilancia y control por parte del órgano al que se refiere la condición $2^{\text {a" }}$.

${ }^{35}$ Circular 1/2016 de la Fiscalía General del Estado, p. 56: "partiendo de que el artículo 31 bis establece un sistema de responsabilidad indirecta o vicarial conforme al cual el fundamento de la responsabilidad penal de la persona jurídica descansa en un hecho ajeno, y no en un hecho propio, la comisión del delito por las correspondientes personas físicas en las condiciones que exige el precepto determinará la transferencia de responsabilidad a la persona jurídica. Ello comporta que con el delito de la persona física nace también el delito de la persona jurídica la cual, no obstante, quedará exenta de pena si resulta acreditado que poseía un adecuado modelo de organización y gestión". 


\subsection{La instauración y gestión de un Canal de Denuncias o Whistleblowing Channel}

Entre los elementos que deben establecerse en el programa de cumplimiento se encuentra el Canal de Denuncias que puede considerarse el epicentro de la documentación que conforma la investigación interna realizada en el seno de la empresa, y comprende tanto documentos como declaraciones o manifestaciones al respecto por los implicados en los hechos.

Nos referimos a este elemento en epígrafe aparte porque resulta clave, tanto en la investigación que se desarrolle a nivel interno en la empresa, como en el posible proceso penal posterior contra la persona jurídica.

La gestión del Canal de Denuncias suele realizarse de forma interna dentro de la empresa, aunque también puede externalizarse para intentar recoger la información con mayor grado de independencia, tal y como recomienda la Fiscalía General del Estado. Con la gestión específica del Canal de Denuncias se eliminan posibles debilidades por la incertidumbre del anonimato del denunciante y la falta de especialización al detectar posibles conductas delictivas. Al instaurarse el Canal de Denuncias deberá informarse a los empleados de su finalidad y su funcionamiento, así como de la confidencialidad del denunciante y las informaciones y datos ${ }^{36}$ que traslade por esa vía, dado que solo puede tener acceso a los datos la persona designada como responsable de cumplimiento normativo y aquellos que investiguen los hechos denunciados. El Canal podrá organizarse de manera telefónica, telemática o presencial. En dicho Canal podrán presentar denuncias o ser denunciados todos los empleados de la empresa.

Recibida una denuncia e identificado el denunciante, en el plazo más breve posible, se informará al denunciado para iniciar la investigación. Si los hechos no logran ser probados se podrá fin a la investigación en dos meses y si se prueban, y procede aplicar el régimen disciplinario o la empresa desea entablar acciones legales, se conservarán los datos para ser aportados en el proceso entablado.

Además de todo lo anterior las empresas deben disponer de un sistema de cumplimiento basado en normas de referencia, auditado, y certificado por

\footnotetext{
${ }^{36}$ Informe Jurídico 128/2007 de la Agencia Española de Protección de Datos. Respecto a la creación de sistemas de denuncias internas en las empresas

https://www.agpd.es/portalwebAGPD/canaldocumentacion/informes_juridicos/otras_cues tiones/common/pdfs/2007-0128_Creaci-oo-n-de-sistemas-de-denuncias-internas-en-lasempresas-mecanismos-de-whistleblowing.pdf
} 
terceros, con su respectivo Código Ético y su régimen disciplinario pues serán un apoyo de gran solidez en el proceso penal para demostrar que se ha hecho todo lo posible para evitar la perpetración de un hecho delictivo en el seno de la empresa.

\section{CONCLUSIONES}

En los últimos años, importantes escándalos empresariales que han tenido su origen en delitos contables, han puesto de manifiesto la necesidad de reformular el sistema actual en aras de evitar la pérdida de confianza en el sistema económico y más en un momento de crisis económico como el actual. De esta manera, se ha vuelto necesario reforzar aún más la independencia de los auditores de cuentas así como potenciar la presencia de los Comités de Auditoría.

En paralelo al desarrollo de las normas contables que han tratado de asegurar que la información financiera refleje la imagen fiel de la situación empresarial, han surgido una serie de técnicas, entre las que destacan la gestión del beneficio, el alisamiento de resultados y la contabilidad creativa, encaminadas a conseguir la manipulación del resultado contable y con ello alterar la imagen fiel que de las cuentas anuales y del resto de información financiera se necesita y espera.

Como conclusión fundamental tenemos que destacar que en las empresas resulta imprescindible, hoy en día, que sus administradores y directivos adopten las medidas necesarias para que cumplir con las obligaciones exigidas por la normativa legal aplicable, implementando los modelos de control y detectando posibles desviaciones para sancionarlas.

El plan de cumplimiento y el Compliance Officer a los cuales hemos hecho referencia en este artículo no pueden ser meras formalidades que vengan impuestas por la legislación vigente, sino que tienen que tener un contenido real y la empresa debe asumir íntegramente la cultura del cumplimiento en su funcionamiento. En este sentido el Compliance debe ser una herramienta básica para la prevención de la comisión de hechos delictivos en el seno de la empresa.

\section{BIBLIOGRAFÍA}

- ALLEGRINI, M., y GRECO, G., "Corporate boards, audit committes and voluntary disclosure: evidence from Italian Listed Companies", en Journal of Management and Governance, 15 (2011) 1-30. 
- AMAT, O., Empresas que mienten. Cómo maquillan las cuentas y cómo detectarlo a tiempo, Barcelona 2007, p. 67.

- AMAT, O., y ELVIRA, O., "Manipulación contable: tipología y prácticas utilizadas", en Revista Internacional Legis de Contabilidad y Auditoría, disponible en http://www.oriolamat.cat/wordpress/wp-content/uploads/2017/04/ Manipulaci\%C3\%B3n-contable-tipolog\%C3\%ADa-y-pr\%C3\%A1cticasutilizadas-Revista-Internacional-Legis-de-Contabilidad-Auditor $\% \mathrm{C} 3 \% \mathrm{ADa}$ 2007.pdf.

- ASTARLOA, E., “¿Por fin un concepto unívoco de administrado de hecho en Derecho penal y Derecho societario?", en Actualidad Jurídica, 1 (2011) 60-67.

- BACIGAlUPO, E., Compliance y Derecho Penal, Editorial Aranzadi, Zizur Menor, 2011.

- CUENCA MÁRQUEZ, J., y CABECERANS CABECERANS, J., "El Compliance Officer y los límites constitucionales de sus investigaciones", en Revista Aranzadi Doctrinal, 2 (2015).

- DÍAZ-MAROTO J., y POLO-VEREDA, J., "Clasificación de las conductas prosociales", disponible en https://starviewerteam.com/2011/06/20/conductaprosocial-empatia-responsabilidad-y-la-ecuacion-de-decision/.

- ENSENYAT DE CARLOS, S., Manual del Compliance Officer. Guía práctica para los responsables de Compliance de habla hispana. Editorial Aranzadi, S.A. Zizur Menor, 2016, pp. 135-138.

- GARCÍA-BENAU, M.A.; PUCHETA-MARTÍNEZ, M.C., y ZORIO-GRIMA, A. "Los Comités de Auditoría ¿útiles y necesarios?”, en Revista de Contabilidad, 6 (2003) 87-121.

- GARCÍA GARCÍA, V., Compliance: funciones especificas que se le deben asignar el Compliance Officer penal, disponible en https://elderecho.com/ funciones-especificas-que-se-le-deben-asignar-al-compliance-officer-penal.

- GELABER-MORRO, F.M., y SANTOS-JAÉN, J. M., "El delito contable. Estudio de la comisión de delitos contables a través de casos mediáticos", en La razón histórica, (Murcia), 45 (2020) 18-41.

- GIMENO BEVIÁ. J. Compliance y proceso penal. El proceso penal de las personas jurídicas. Editorial Aranzadi S.A, Zizur Menor, 2016. 
EL DELITO CONTABLE Y LA NECESIDAD DE IMPLEMENTAR PROGRAMAS... 117

- GÓMEZ-JARA DÍEZ, C. La responsabilidad penal de las empresas en los Estados Unidos, Centro de Estudios Ramón Areces, Madrid 2006.

- LEÓN ALAPONT, J., "Los programas de cumplimiento penal como objeto de prueba", en Revista General de Derecho Procesal, 51 (2020).

- MONFORTE MAYORAL, J., "Entre la contabilidad creativa y el delito contable", en Diario La Ley, el 17 de abril, (2020) págs.1-7.

- NEIRA PENA, A.M. Proceso penal y responsabilidad penal de las personas jurídicas. Editorial Aranzadi, S.A.U, Zizur Menor, 2017.

- OLMEDO PERALTA, E., La responsabilidad contable en el gobierno corporativo de las sociedades de capital, Madrid 2014, p. 83.

- PALACIOS-MANZANO, M.; GRAS-GIL, E., y SANTOS-JAÉN, J.M., "Corporate Social Responsibility and its effect on earnings managements: an empirical research on Spanish firms", en Total Quality Management and Business Excellence (Londres), 3 (2020) 82-111.

- PAVÓN-HERRADÓN, D., El delito de falsedad en los documetnos sociales del artículo 290 del código penal, [Universidad Complutense de Madrid], disponible en http://www.javeriana.edu.co/biblos/tesis/derecho/dere1/Tesis 35.pdf.

- RAYÓN BALLESTEROS, M.C., Los programas de cumplimiento penal: origen, regulación, contenido y eficacia en el proceso, Anuario Jurídico y Económico Escurialense, 51 (2018) 197-222.

- RAYÓN BALLESTEROS, M.C., y PESQUERA, E., "Cuestiones clave de las once primeras sentencias del Tribunal Supremo sobre la responsabilidad penal de la persona jurídica", en Revista de Derecho y Proceso Penal, 50 (2018) 279307.

- ROMERO-GARCÍA, J.E.; LÓPEZ-GAVIRA, M. R., y PÉREZ-LOPEZ, J. A., "Servicios adicionales de auditoría. Independencia del auditor y permisividad de la legislación”, en Revista de Ciencias Sociales, 4 (2017) 9-22.

- RUBIO-HERRERA, E., "El deber de independencia de los auditores según la nueva normativa”, en Revista Española de Control Externo, 52 (2016) 59-101. 
